\title{
Circular dichroism is sensitive to monovalent cation binding
}

\section{in Monensin complexes}

\author{
Ahmed Nedzhib, ${ }^{[a]}$ Jiří Kessler, ${ }^{[b]}$ Petr Bouř, ${ }^{*[b]}$ Béla Gyurcsik, ${ }^{[c]}$ and Ivayla Pantcheva, ${ }^{*[a]}$
}

Abstract: Monensin is a natural antibiotic that exhibits high affinity to certain metal ions. In order to explore its potential in coordination chemistry, circular dichroism spectra of Monensic acid $\mathrm{A}(\mathrm{MonH})$ and its derivatives containing monovalent cations $\left(\mathrm{Li}^{+}, \mathrm{Na}^{+}, \mathrm{K}^{+}, \mathrm{Rb}^{+}, \mathrm{Ag}^{+}\right.$and $\left.\mathrm{Et}_{4} \mathrm{~N}^{+}\right)$in methanolic solutions were measured and compared to computational models. Whereas the conventional CD spectroscopy (CD) allowed recording of the transitions down to $192 \mathrm{~nm}$, synchrotron radiation circular dichroism (SRCD) revealed other bands in the 178-192 nm wavelength range. CD signs and intensities significantly varied in the studied compounds, in spite of their similar crystal structure.
Computational modelling based on the density functional theory (DFT) and continuum solvent model suggests that the solid state Monensin structure is largely conserved in the solutions as well. Time-dependent density functional theory (TDDFT) simulations did not allow band-to-band comparison with experimental spectra due to their limited precision, but indicate that the spectral changes are caused by a combination of minor conformational changes upon the monovalent cation binding and a direct involvement of the metal electrons in Monensin electronic transitions. Both the experiment and simulations thus show that the CD spectra of Monensin complexes are very sensitive to the captured ions and can be used for their discrimination.

Keywords: monovalent polyether ionophore, metal complexes, synchrotron radiation circular dichroism, time-dependent density functional theory

\section{Introduction}

Monensin is a natural antibiotic produced by Streptomyces cinnamonensis. ${ }^{1-3}$ It is widely applied in stock farming and veterinary medicine due to its pronounced coccidiostatic and antibacterial properties. ${ }^{4-14}$ The main form of the ionophore is Monensin A (Monensic acid, MonH), accompanied by two minor factors, Monensin B and Monensin C, also produced by the Streptomyces bacteria. From a chemical point of view, Monensin $\mathrm{A}$ is a polyether derivative of a monocarboxylic acid (Scheme 1). Its monohydrated form $\left(\mathrm{MonH} \times \mathrm{H}_{2} \mathrm{O}\right)$ exists in a pseudo-cyclic conformation secured by head-to-tail $\mathrm{H}$-bonding between the carboxylic moiety and the alcoholic hydroxyl group (of the last six-membered ring 011), with a supplementary binding of a water molecule. ${ }^{15,16}$ Oxygen atoms pointing inside the cavity ensure its hydrophilic character, while the alkyl-rich polyether backbone provides antibiotic lipophilicity and corresponding cell membrane activity.

\section{SCHEME 1}

Another interesting property of Monensin is its ability to form complexes with certain monovalent metal cations. The antibiotic acts as a monoanion through deprotonated carboxylic function, assuring an overall neutral charge of the complex. These complexes can also easily penetrate bacteria's cell membranes via the so called electrogenic and nonelectrogenic mechanisms. ${ }^{17-24}$ Inside the cell dissociation processes occur, leading to disturbance of $\mathrm{pH}$ and metal ion equilibria. Subsequent changes activate a variety of further events, ultimately leading to cell death. Better understanding of the metal ion complexation of Monensin in solution will contribute to elucidation of the details of the above processes.

The affinity of Monensin to bind monovalent metal ions decreases in the order of $\mathrm{Ag}^{+}>\mathrm{Na}^{+}>\mathrm{K}^{+}>\mathrm{Rb}^{+}>\mathrm{Li}^{+} \sim \mathrm{Cs}^{+} .{ }^{25}$ Molecular geometries of complexes with lithium, sodium, potassium, rubidium, and silver cations were determined by $\mathrm{X}$ ray diffraction on single crystals. ${ }^{26-35}$ The crystal forms are very

[a] MSc A. Nedzhib, Assoc. Prof. I. Pantcheva Department of Analytical Chemistry Faculty of Chemistry and Pharmacy Sofia University "St. KI. Ohridski"

1, J. Bourchier blvd., 1164 Sofia, Bulgaria

Fax: (+)359-2-9625438

E-mail: ahan@chem.uni-sofia.bg,

ipancheva@chem.uni-sofia.bg

[b] MSc J. Kessler, Prof. P. Bour Institute of Organic Chemistry and Biochemistry Academy of Sciences

2, Flemingovo nám., 16610 Prague, Czech Republic E-mail: kessler@uochb.cas.cz,petr.bour@uochb.cas.cz

[c] Assoc. Prof. B. Gyurcsik

Department of Inorganic and Analytical Chemistry University of Szeged

7, Dóm tér, Szeged, Hungary

E-mail:gyurcsik@chem.u-szeged.hu 
similar, with the monovalent metal ion trapped into the central cavity and coordinated at least with six oxygen $(-\mathrm{O}-,-\mathrm{OH})$ donor atoms. Carboxylate oxygens do not participate in the binding, but two hydrogen bonds between the carboxylate group and alcoholic $\mathrm{OH}$ groups at the opposite end of the molecule stabilize the pseudo-cyclic structure, which is slightly differently than in a free ligand.

MonH and its monovalent metal complexes exhibit a very low solubility in water, but are readily soluble in methanol, ethanol, acetone, or chloroform. These solutions were studied in potentiometric, ${ }^{36-42} \mathrm{NMR},{ }^{43-47}$ polarographic, ${ }^{48}$ and massspectrometric $^{49-54}$ experiments. Natural polyether ionophores, as lasalocid and salinomycin were studied by $C D$ in the near UV range, ${ }^{55-59}$ but in the lack of suitable chromophores this technique was not employed so far for Monensin.

Let us recall that the usage of the CD spectroscopy, at least as a complementary method, appears convenient for many reasons. It is in general more sensitive with respect to the sample amount and structural changes than infrared absorption, the experiment is simpler than X-ray diffraction, NMR or massspectroscopy, it is applicable to solutions unlike X-ray diffraction, etc. On the other hand, $C D$ often provides rather limited resolution and number of spectral features; these disadvantages can be at least partially sorted out by the possibility to interpret the spectra on the basis of parameterfree quantum-chemical computations.

In the present paper the potency of conventional circular dichroism (CD) and synchrotron radiation circular dichroism (SRCD) spectroscopy is explored to evaluate complexation ability of Monensin A with respect to monovalent cations in solution. The experimental data are discussed on the basis of computational modelling. Density functional theory (DFT) and a dielectric solvent model are used to estimate solution geometries, and time-dependent DFT (TDDFT) is used to simulate the absorption and CD spectra.

\section{Materials and Methods}

\section{MATERIALS}

Sodium Monensinate (MonNa) was kindly provided by Biovet Ltd. (Peshtera, Bulgaria). Metal(I) salts, Et $\mathrm{H}_{4} \mathrm{NOH}$ and methanol of analytical grade were supplied by Merck / Fluka.

Monensic acid $\left(\mathrm{MonH} \times \mathrm{H}_{2} \mathrm{O}\right)$, tetraethylammonium Monensinate $\left(\mathrm{MonNEt}_{4}\right)$ and monovalent metal complexes MonM $(\mathrm{M}=\mathrm{K}, \mathrm{Rb}$, $\mathrm{Li}, \mathrm{Ag}$ ) were prepared as described previously. ${ }^{26,40}$ The complex formation was confirmed by IR spectroscopy (Fig. S1, FT-IR Nikolet 6700 spectrophotometer, Thermo Scientific, KBr pellet). Isolated solid state Monensin complexes were dissolved in methanol for subsequent measurements. The data from titrations of MonH with monovalent metal ions fit well these (Fig. S2). MonNEt $_{4}$ was obtained in situ.

\section{SPECTROSCOPY}

CD spectroscopic measurements were performed on a JASCO $\mathrm{J}-815$ spectrometer with solution samples (concentration of 5-20 $\mathrm{mmol} \mathrm{dm}{ }^{-3}$, temperature of $25^{\circ} \mathrm{C}$ ) kept in a fused silica cuvette of $0.2 \mathrm{~mm}$ optical pathlength. The spectra were recorded in the
180-300 $\mathrm{nm}$ range, using $0.5 \mathrm{~nm}$ resolution, $2 \mathrm{~s}$ response time, and a scanning speed of $20 \mathrm{~nm} / \mathrm{min}$.

Synchrotron radiation $C D$ (SRCD) spectra were recorded at the AU-CD beam line SRCD facility, part of the ASTRID2 storage ring at the Institute for Storage Ring Facilities (ISA), University of Aarhus, Aarhus, Denmark. ${ }^{60,61}$ The compounds were dissolved in methanol to concentrations of $40-100 \mathrm{mmol} \mathrm{dm}^{-3}$. All spectra were recorded at $24.4{ }^{\circ} \mathrm{C}$ in $1 \mathrm{~nm}$ steps with a dwell time of $2 \mathrm{~s}$ per step, in the wavelength range of $170-300 \mathrm{~nm}$ and with resolution of $0.5 \mathrm{~nm}$. Spectra of sodium Monensinate (MonNa) were recorded using both $0.2 \mathrm{~mm}$ and $0.014 \mathrm{~mm}$ cuvettes, whereas $0.014 \mathrm{~mm}$ only was used for the rest.

Two accumulations were averaged both for the CD and SRCD measurements. The molar absorbance and molar ellipticity of compounds were calculated after subtraction of the solvent (methanol) spectra acquired at identical conditions.

\section{CALCULATIONS}

X-ray structures of Monensic acid (MonH $\left.\times \mathrm{H}_{2} \mathrm{O}-\mathrm{MONSNI}\right)^{15}$ and its monovalent metal complexes MonM $\left(\mathrm{M}=\mathrm{Li}^{+}-\mathrm{MIPSIO},{ }^{33} \mathrm{Na}^{+}\right.$ - DEYGAQ, ${ }^{32} \mathrm{~K}^{+}$- FECROU10, ${ }^{30} \mathrm{Rb}^{+}$- RITLIQ, ${ }^{34} \mathrm{Ag}^{+}$-

MONSIN $10^{26}$ ) were used as starting geometries. The structures were fully optimized in the Gausian09.Rev.D01 program ${ }^{62}$ using the B3LYP functional ${ }^{63}$ and the conductor-like polarizable continuum solvent model (CPCM) ${ }^{64}$ to account for the methanol environment. CAM-B3LYP invented to improve B3LYP. B3PW91, LC-WPBE and WB97XD functionals were also applied, but did not give better results than the standard B3LYP (Fig. S3).

Alternatively to the full optimization, X-ray geometries, partially optimized in the normal mode coordinates were used as well; normal modes with frequencies $\left|\omega_{\mathrm{i}}\right|<300 \mathrm{~cm}^{-1}$ were fixed. ${ }^{65}$ The partial optimization corrected in particular bond lengths and angles of the hydrogen atoms, determined with a big error or completely missing in the crystal structures.

The $6-311++G^{* *}$ basis set was used for the carboxyl group atoms, the MWB28 pseudopotential ${ }^{66}$ and basis set were used for silver and rubidium atoms, and the $6-31 \mathrm{G}^{\star *}$ basis set was used for the rest. For the optimized structures, UV and CD spectra were calculated at the TDDFT ${ }^{67}$ / CPCM level. For each system 100 electronic excited states were obtained to cover the experimentally observable spectral range.

\section{Results and Discussion}

To the best of our knowledge we report for the first time the spectral changes occurring upon complexation of Monensin A, evaluated by means of CD spectroscopy. As some readers might not be familiar with the SRCD technique, we compare classical CD and SRCD measurements done using the same 0.2 $\mathrm{mm}$ optical pathlength cell. The CD and SRCD spectra of sodium Monensinate (MonNa), as well as, the total absorbances derived from the same measurements are plotted in Fig. S4. The careful comparison of the two techniques in this setup showed only minor differences. Keeping the total absorbance value below 2 is a prerequisite to obtain reliable CD spectra. By means 
of conventional $C D$ and SRCD under the same experimental conditions such data were obtained in the UV range down to 192 and $187 \mathrm{~nm}$, respectively. In both CD and SRCD the absorbance of the solvent used $(\mathrm{MeOH})$ with and without $\mathrm{MonNa}$ is almost the same demonstrating the negligible contribution of the dissolved substance to the total absorbance. The CD and SRCD spectra of MonNa correspond reasonably well to each other. Below $192 \mathrm{~nm}$, the conventional CD quickly deteriorates due to the high absorption and low sensitivity.

The CD spectra of MonH and all the monovalent complexes (recorded at $0.2 \mathrm{~mm}$ optical pathlength) are presented in Fig. 1. The results show that position and sign of CD signals significantly depend on the protonation state of the ligand and coordinated cation. MonH, for example, exhibits positive sign within 190-245 nm with two maxima at 218 and $192 \mathrm{~nm}$, while the replacement of $\mathrm{H}^{+}$with the $\mathrm{Et}_{4} \mathrm{~N}^{+}$cation diminishes the 218 $\mathrm{nm}$ band (although it remains still positive) and gives rise to a positive maximum at $195 \mathrm{~nm}$. The observed spectral variance can be probably attributed to formation of an alternative hydrogen-bonding network. Most probably, MonH stays in the "closed" conformation as it was found most favourable for the anionic form. ${ }^{15,68}$

\section{FIGURE 1}

The trapping of monovalent metal ions into the ligand cavity causes significant changes in the CD spectra. The complexation of sodium ions is accompanied by appearance of two bands, at $200 \mathrm{~nm}$ (positive) and $216 \mathrm{~nm}$ (negative). The coordination of lithium ions provides a negative signal within 190-230 nm, while the CD spectrum of the silver complex contains positive (196 $\mathrm{nm}$ ) and negative (208 $\mathrm{nm}$ ) bands. The potassium and rubidium complexes of Monensin are mostly characterized by negative bands at $201-203 \mathrm{~nm}$.

We were able to obtain additional data in the far UV region by SRCD spectroscopy using a shorter optical pathlength of 0.014 $\mathrm{mm}$ (Fig. 2). The spectra were cut at $178 \mathrm{~nm}$ by the limitation due to the high absorbance values ( $\mathrm{HT}>5$ below this wavelength). Absorption spectra of all compounds are quite similar, except for the MonAg with a characteristic shoulders at longer wavelengths (200 and $218 \mathrm{~nm}$ ). The absorption intensity generally increased upon exchange of $\mathrm{H}^{+}$with monovalent cations. Low-wavelength $C D$ bands unseen by conventional $C D$ are of high intensity and provide additional possibility to distinguish different Monensin complexes. The experimental spectra of MonH and MonNEt $_{4}$ possess negative signal below $190 \mathrm{~nm}$, and silver complex has a strong negative band at 185 $\mathrm{nm}$. The coordination of lithium ions leads to appearance of a negative band at $187 \mathrm{~nm}$ accompanied by a negative shoulder at c.a. $200-220 \mathrm{~nm}$. Spectral shapes of the MonK and MonRb complexes in the range of $180-185 \mathrm{~nm}$ differ, in spite of the similarities observed within the $190-220 \mathrm{~nm}$ interval. The sodium complex of Monensin provides a unique spectrum, too.

Figure 2

The comparison of CD and SRCD spectra reveals a very good agreement in the range of 192-300 $\mathrm{nm}$. The SRCD technique leads to higher signal to noise ratio, and the SRCD setup with the thin $0.014 \mathrm{~mm}$ cell provides characteristic, high intensity signal even within the 178-192 $\mathrm{nm}$ region of a high absorption. ${ }^{60,61}$

Structural changes upon metal binding may account for such differences in CD spectra. However, these are quite small. The structures of Monensin A and its metal complexes were compared; the root-mean-square deviations (RMSD) ${ }^{69}$ obtained using the PyMol alignment procedure are collected in Table I. We see that the overall conformation of the ligand is very similar in each complex. Despite this similarity observed also in the IR and NMR spectra of monovalent Monensinates, ${ }^{32,33,35,47}$ the CD spectra differ significantly in band positions, signs and intensities. Nevertheless, some trends can be observed. The fine structure of MonH differs from those of the metal complexes (RMSD 0.7; Fig. S5), which may be reflected in the CD intensities (Fig. 3). Both the MonLi and MonNa, and MonK and MonRb crystal pairs look rather similar (RMSD 0.2; Fig. S6), in accordance with the good agreement in the wavelengths of CD minima and maxima.

Considering that there is no significant change in the overall structures of the species when dissolved in methanol - which can also be supposed from NMR data published earlier ${ }^{45-47}-$ at least some differences in the CD spectra might be explained by the small conformational changes of the ligand molecule upon complexation. On the other hand, the crystal structure of MonAg, which is also different from MonH and is rather similar to MonM structures (e.g. RMSD $\sim 0.1$ for the comparison with MonNa, Fig $\mathrm{S} 7)$, has a rather unique $C D$ spectrum.

Calculated absorption and CD spectra (Fig. 2) may provide better understanding of the problem, although they do not reproduce the experiment quantitatively. The absorption spectra exhibit a limited number of features to be compared, except for the outstanding high-wavelength absorption of the Ag derivative. The fully-optimized geometries (middle panel) provide better absorption profile of the K-derivative, otherwise they do not exhibit a clear advantage against the $\mathrm{X}$-ray model (bottom).

Occasional agreement of calculated and experimental CD spectra can be observed. For example both spectra of $\mathrm{MonH}$ are negative around $180 \mathrm{~nm}$. The measured curve is positive above $\sim 185 \mathrm{~nm}$, but the calculation predicts a negative signal at higher wavelengths that is not observed experimentally. Part of the disagreement can be given by the position of hydrogen atoms, not clearly given by the X-ray data. The usual error of the TDDFT method ${ }^{(70)}$ and complicated conformational and hydration equilibria that could not be included in the calculations due to excessive computational demands also hinder a more detailed comparison of calculated and experimental CD intensities.

On the other hand, the calculations well-document the sensitivity of Monensin to the metal binding. Also, based on the orbital analysis, we could also assign the most prominent spectral features. Thus most transitions around $180 \mathrm{~nm}$ in monovalent Monensinates (except the $\mathrm{Ag}^{+}$-derivative) are $\sigma \rightarrow \sigma^{*}$; transitions within 190-200 nm can be approximately thought of as $\sigma \rightarrow \sigma^{*}$, and within 200 to $206 \mathrm{~nm} \mathrm{n} \rightarrow \sigma^{*}$ transitions dominate (" $n$ " means a non-bonding (lone pair) orbital on oxygen in hydroxyl or carboxyl). Most but not all transitions above $180 \mathrm{~nm}$ are located around the carboxyl residue. The highest wavelength bands around $210-215 \mathrm{~nm}$ are attributed to $\sigma \rightarrow \pi^{*}$ and $\mathrm{n} \rightarrow \pi^{*}$ 
transitions, where the $\pi$-orbitals mostly belong to the carboxyl, although a small participation of the lone pairs on hydroxyl oxygen can be also counted as $\pi$. With silver cation, the situation is different, as the silver transitions are stronger and dominate all the 180, 215, 230 and $242 \mathrm{~nm}$ intense bands are assigned to $4 \mathrm{~d} \rightarrow 5 \mathrm{~s}$ transition; the $\mathrm{n}, \pi$ and $\sigma$ orbitals of Monensin also contribute as above, but their contribution is weaker.

The spectra generated with the partially optimized structures (lower part of Fig. 2) provide very similar results in terms of agreement/disagreement with the experiment, which also suggest that the overall ligand geometries are rather similar. However, it should be mentioned that e.g. for MonK and MonRb the spectra calculated for the partially optimized ("crystal") geometry compare better to experimental CD than that those obtained for the fully optimized structure.

Thus, although the calculations do not reproduce well detailed experimental $C D$ patterns, they confirm that the metal ions can induce specific $C D$ shapes under a minimal change of conformation. The limited accuracy can be explained by the complexity of the system and accumulation of computational error stemming from the DFT and TDDFT approximations, approximate solvent model and lack of dynamics in the modelling. Yet several trends could be observed, such as the profound difference in the behaviour of the $\mathrm{Ag}^{+}$-ion if compared to the others.

To understand better the link between the spectrum and the structure, we performed various computational experiments. In Fig. 3, simulated absorption and $\mathrm{CD}$ spectra for the $\mathrm{Li}^{+}, \mathrm{Na}^{+}, \mathrm{K}^{+}$, $\mathrm{Rb}^{+}$and $\mathrm{Ag}^{+}$complexes, and their counterparts with the same ligand structure but metal ions removed, are plotted. The spectral shapes and the pairwise comparison demonstrate that the metal ion can significantly affect the spectrum participating in electronic transitions and inducing changes in the ligand fine structure. We marked the position of the highest-wavelength (lowest-energy) electronic transition for different metal complexes. As expected, this "threshold" transition largely involves the HOMO and LUMO orbitals. Both the position and relative intensity of these bands vary for different metal ions, with the $\mathrm{Ag}^{+}$-ion causing the largest shift of the absorption band to longer wavelength, in agreement with the experiment.

\section{Figure 3}

On a qualitative level, one can see the influence of the metal ion binding on electronic structure in Fig. 4, where the HOMO and LUMO orbitals are exemplified for the $\mathrm{MonH}$ and its monovalent derivatives. Apparently, in most metal complexes, the orbitals, in particular HOMO, shift closer to the molecular site where the metals are bound. The $\mathrm{Ag}^{+}$complex is an exception, with HOMO being relatively far from the metal, but the LUMO shape is unique due to the participation of the $\mathrm{Ag} 5 \mathrm{~s}$ orbital. The delocalization of the orbitals lends CD spectra additional sensitivity to fine conformational changes.

\section{Figure 4}

The comparison of the optimized structures gives a similar picture as for the crystal structures (Table I). The metal complexes do not deviate much from MonH and the pairwise similarity of MonLi and MonNa can still be recognized (RMSD 0.2 ). The increase of the size of the metal ion, however, seems to increase discrepancies between the X-ray and computed geometries. This can be demonstrated by the RMSD values derived from the comparison of each crystal structure and its optimized counterpart (first column in Table I). While these numbers for MonH, MonLi and MonNa are below 0.2, they increase for MonK, MonRb and also for MonAg. The strict similarity between MonK and MonRb has been lost (RMSD 0.7 ), as well.

Table I

Table II and Fig S8 provide more details of the fine structural changes during the optimization process. By the comparison of the probable hydrogen bonding scheme between the two termini of the Monensinate ion in different complexes, we can state that the most significant fine changes occurred in the MonK and MonAg structures. In addition the $\mathrm{M}-\mathrm{O}$ atomic distances also vary in the MonK complex as the carboxylate oxygens approached the metal ion during the optimization. The original distance of $\mathrm{K}^{+}$from both carboxylate oxygens is $\sim 3.5 \AA$ and from the coordinated oxygens is around $2.7 \AA$, while in the optimized structure, the carboxylate oxygen-metal ion distances are $\sim 2.9 \AA$ and the other oxygens are at 2.8-2.9 $\AA$, a little bit further from the metal ion than in initial structure. In the metal ion bonding network of the MonRb complex there are gradual changes of the distances, but the overall structure and the coordination mode seems to be the same as in the crystal.

Table II

The differences might reflect approximations (solvent model, limited basis set, functional) used in the calculations, but such small deviations between the solution and crystal structures may also be realistic. As was pointed out in the reviewing process, the experiments in methanol may also be biased due to residual traces of water (potentially bound to Monensin) that are difficult to control. In any case, the overall similarity of the crystal and fully optimized DFT structures of the metal complexes of Monensin contrast with their different CD spectral patterns. In general, we can thus conclude that while it is difficult to estimate extent of the geometry change when the crystals are dissolved in methanol, the comparison of calculated and experimental spectral patterns can provide useful indications.

\section{Conclusion}

In order to explore the unique metal-binding properties of the Monensin A antibiotic, we recorded and analysed CD and SRCD spectra of its complexes with ammonium, light and heavy monovalent metal ions. The SRCD technique provided higher signal-to-noise ratio and enabled measurement in a wider wavelength range than $\mathrm{CD}$. Except for the $\mathrm{Ag}^{+}$-ion, the metal ion binding did not significantly influence the absorption spectrum, whereas significant changes occurred in CD. This behaviour was on a qualitative level explained by time-dependent density functional computations of solution geometries and excitation spectra. These confirmed that incorporation of monovalent cations into the antibiotic structure does not significantly change the solid state conformation, but that the cation directly 
participates in the electronic transitions which may be largely responsible for the $C D$ pattern changes. Because of the large and metal-specific spectral variations under the binding, we can thus conclude that the $C D$ spectroscopy can be used as a sensitive indicator of Monensin A monovalent cation binding.

\section{Acknowledgements}

Financial support of TÁMOP-4.2.4.A/2, John von Neumann International Scholarship for senior foreign teachers-researchers \& CALIPSO Programme (FP7/2007-2013, grant $n^{\circ} 312284$ ) is greatly acknowledged. In the Czech Republic, the work was also supported by the Grant Agency (16-05935S, 13-03978S and 1509072S), and MetaCentrum computational grants LM2010005 and CZ.1.05/3.2.00/08.0144. The authors are thankful to Eszter Nemeth for the valuable discussion on PyMol alignment procedure.

\section{Supporting information}

Additional supporting information may be found in the online version of this article at the publisher's website.

\section{REFERENCES AND NOTES}

1. Haney ME Jr, Hoeln MM. Monensin, a new biologically active compound. I. Discovery and isolation. Antimicrob Agents Chemother (Bethesda) 1967;7:349-352.

2. Agtarap A, Chamberlin JW. Monensin, a new biologically active compound. IV. Chemistry. Antimicrob Agents Chemother (Bethesda) 1967a; 7:359-362.

3. Agtarap A, Chamberlin JW, Pinkerton M, Steinrauf LK. The structure of monensin acid, a new biologically active compound, J Am Chem Soc 1967b;89: 5737-5739.

4. Pressman BC, Biological application of ionophores. Ann Rev Biochem 1976; 45:501-529.

5. Stern PH. Ionophores: chemistry, physiology and potential applications to bone biology. Clin Orthop Rel Res 1977;122:273298.

6. Long PL, Jeffers TK. Studies on the stage of action of ionophorous antibiotics against Eimeria. J Parasitol 1982;68:363-371.

7. Augustine PC, Smith CK, Danforth HD, Ruff MD. Effect of ionophorous anticoccidials on invasion and development of Eimeria: comparison of sensitive and resistant isolates and correlation with drug uptake. Poultry Sci 1987;66:960-965. 8. Koinarski V, Sherkov SN. Effect of anticoccidial preparations in the prevention of coccidiosis in turkeys caused by Eimeria adenoides. Vet Med Nauki 1987;24;81-85.

9. Folz SD, Lee BL, Nowakowski LH, Conder GA. Anticoccidial evaluation of halofuginone, lasalocid, maduramicin, monensin and salinomycin. Vet Parasitol 1988;28;1-9.

10. Augustine PC, Watkins KL, Danforth HD. Effect of monensin on ultrastructure and cellular invasion by the turkey coccidia Eimeria adenoeides and Eimeria meleagrimitis. Poultry Sci 1992; 71:970-978.

11. Dutton CJ, Banks BJ, Cooper CB. Polyether ionophores. Nat Prod Rep 1995;12:165-181.

12. Page SW. The role of enteric antibiotics in livestock production. Canberra: Avcare Ltd.; 2003, 338 p.

13. Wang Z, Suo X, Xia X, Shen J. Influence of monensin on cation influx and $\mathrm{Na}^{+}-\mathrm{K}^{+}$- ATPase activity of Eimeria tenella sporozoites in vitro. J Parasitol 2006;92:1092-1096.

14. Kevin II DA, Meujo DAF, Hamann MT. Polyether ionophores: broad-spectrum and promising biologically active molecules for the control of drug resistant bacteria and parasites. Expert Opin Drug Discov 2009;4:109-146.
15. Lutz WK, Winkler FK, Dunitz JD. Crystal structure of the antibiotic monensin: similarities and differences between free acid and metal complex. Helv Chim Acta 1971;54:1103-1108. 16. Anteunis MJO, Rodios NA. Solution conformation of monensin free acid, a typical representative of the polyetherin antibiotics, Bioorg Chem 1978;7:47-55.

17. Pressman BC. Ionophorous antibiotics as models for biological transport. Fed Proc 1968; 27:1283-1288.

18. Lutz WK, Wipf HK, Simon W. Alkali cation specificity and carrier properties of antibiotics nigericin and monensin. Helv Chim Acta 1970;53:1741-1746.

19. Pressman BC, Deguzman NT. Biological applications of ionophores - theory and practice. Ann NY Acad Sci 1975;264:373-386.

20. Westley JW. Polyether antibiotics, naturally occurring acid ionophores. New York: Marcel Dekker; 1982, Vol. I and II. 21. Antonenko YN, Yaguzhinsky LS. The ion selectivity of nonelectrogenic ionophores measured on a bilayer lipid membrane: nigericin, monensin, A23187 and lasalocid A. Biochim Biophys Acta 1988;939:125-130.

22. Prabhananda BS, Kombrabail MH. Monensin-mediated transports of $\mathrm{H}+, \mathrm{Na}+, \mathrm{K}$ and $\mathrm{Li}+$ ions across vesicular membranes - T-jump studies. Biochim Biophys Acta 1992;1106:171-177.

23. Huczynski A, Janczak J, Lowicki D, Brzezinski B. Monensin $A$ acid complexes as a model of electrogenic transport of sodium cation. Biochim Biophys Acta - Biomembranes 2012;1818:21082119.

24. Antonenko YN, Rokitskaya TI, Huczyński A. Electrogenic and nonelectrogenic ion fluxes across lipid and mitochondrial membranes mediated by monensin and monensin ethyl ester. Biochim Biophys Acta 2015;1848:995-1004.

25. Cox BG, Van Truon N, Rzeszotarska J, Schneider H, Rates and equilibria of alkali metal and silver ion complex formation with monensin in ethanol, J Am Chem Soc 1984;106:5965-5969. 26. Pinkerton M, Steinrauf LK. Molecular structure of monovalent metal cation complexes of monensin. J Mol Biol 1970;49:533546 .

27. Duax WL, Smith GD, Strong PD. Complexation of metal ions by monensin - crystal and molecular structure of hydrated and anhydrous crystal forms of sodium monensin. J Am Chem Soc 1980;102:6725-6729.

28. Barrans PY, Alleaume M, Jeminet G. Complexe de sodium de l'ionophore monensine B monohydrate. Acta Cryst 1982;B38:1144-1149.

29. Walba DM, Hermsmeier M, Haltiwanger RC, Noordik JH. Crystal structures of monensin B lithium and silver salts. J Org Chem 1986;51:245-247.

30. Pangborn W, Duax WL, Langs D. The hydrated potassium complex of the ionophore monensin A. J Am Chem Soc 1987; 109:2163-2165.

31. Paz FAA, Gates PJ, Fowler S, Gallimore A, Harvey B, Lopes NP, Stark CBW, Staunton J, Klinowski J, Spencer JB. Sodium monensin dihydrate. Acta Cryst 2003;E59:m1050-m1052. 32. Huczynski A, Ratajczak-Sitarz M, Katrusiak A, Brzezinski B. Molecular structure of the 1:1 inclusion complex of monensin $A$ sodium salt with acetonitrile. $J$ Mol Struct 2007a;832:84-89. 33. Huczynski A, Ratajczak-Sitarz M, Katrusiak A, Brzezinski B. Molecular structure of the 1:1 inclusion complex of monensin $A$ lithium salt with acetonitrile. J Mol Struct 2007b;871:92-97. 34. Yildirim SO, McKee V, Khardli FZ, Mimouni M, Hadda TB. Rubidium (I) monensinate dihydrate. Acta Cryst 2008;E64:m154m155.

35. Huczynski A, Ratajczak-Sitarz M, Katrusiak A, Brzezinski B. Molecular structure of rubidium six-coordinated dihydrate complex with monensin A. J Mol Struct 2008;888:224-229. 36. Hoogerheide JG, Popov Al. Study of monensin complexes with monovalent metal ions in anhydrous methanol solutions. $J$ Sol Chem 1978; 7:357-372.

37. Garcia-Rosas J, Schneider H, Cox BG, Silver complexation by the ionophorous antibiotic monensin in nonaqueous solvents. J Phys Chem 1983;87:5467-5472. 
38. Cox BG, Van Truong N, Rzeszotarska J, Schneider H. Stability constants of complexes of monensin and lasalocid with alkali-metal and alkaline-earth-metal ions in protic and polar aprotic solvents. J Chem Soc, Faraday Trans. I 1984a;80:32753284.

39. Mimouni M, Perrier S, Pointud I, Juillard J. Selectivity of bacterial ionophore monensin for monovalent metal cations. Solvent effects in methanol and biphasic water-organic systems. J Sol Chem 1993;22:769-785.

40. Gertenbach PG, Popov Al. Solution chemistry of monensin and its alkali metal ion complexes. Potentiometric and spectroscopic studies. J Am Chem Soc 1975;97:4738-4744. 41. Hoogerheide JG, Popov AI. A study of metal complexes of a naturally occurring macrocyclic ionophore Monensin. J Sol Chem 1979;8:83-95.

42. Pointud Y, Bernard C, Touzain S, Astier L, Sabatier B,

Juillard J. Thermodynamics of complexation of monovalent metal cations by the ionophore monensin free acid in acetonitrile, $J$ Sol Chem 1997;26:479-495.

43. Degani $\mathrm{H}$, Kinetics of monensin complexation with sodium ions by ${ }^{23} \mathrm{Na}$ NMR spectroscopy. Biophys Chem 1977;6:345-349. 44. Briggs RW, Hinton JF, Thallium-205 and proton nuclear magnetic resonance investigation of the complexation of thallium by the ionophores monensin and nigericine. Biochemistry 1978; $17: 5576-5582$.

45. Turner DL, The conformation of the monensin-A-sodium Complex in solution determined from self-consistent NOE distance constraints. J Magn Reson B1995;108:137-142. 46. Mimouni M, Hebrant M, Dauphin G, Juillard J. Monovalent cation salts of the bacterial ionophore monensin in methanol. Structural aspects from NMR experiments. J Chem Res 1996;S6:278-279.

47. Martinek T, Riddell FG, Wilson C, Weller CT, The conformations of monensin-A metal complexes in solution determined by NMR spectroscopy. J Chem Soc, Perkin Trans 2 2000;35-41.

48. Filipek S, Rzeszotarska J, Kalinowski MK, Polarographic study of $\mathrm{Tl}^{+}, \mathrm{Li}^{+}, \mathrm{Na}^{+}, \mathrm{K}^{+}$, and $\mathrm{Cs}^{+}$complexes with monensin anion in dipolar aprotic solvents, Monatshefte flit Chemie 1994;125:801-809.

49. Chamberlin JW, Agtarap A. Observations on the mass spectrometry of monensin and related compounds. Org Mass Spectrom 1970:3:271-285.

50. Havlicek V, Ryska M, Pospisil S. Negative-ion fast atom bombardment tandem mass spectrometry of sodium salts of monensins and related compounds. J Mass Spectrom 1995; 30:1089-1094.

51. Lopes NP, Stark CBW, Hong H, Gates PJ, Staunton J. A study of the effect of $\mathrm{pH}$, solvent system, cone potential and the addition of crown ethers on the formation of the monensin protonated parent ion in electrospray mass spectrometry. Analyst 2001;126:1630-1632.

52. Lopes NP, Stark CBW, Hong H, Gates PJ, Staunton J. Fragmentation studies on monensin $A$ and $B$ by accurate-mass electrospray tandem mass spectrometry, Rapid Commun Mass Spectrom 2002; 16:414-420.

53. Miao XS, March RE, Metcalfe CD. Fragmentation study of salinomycin and monensin $A$ antibiotics using electrospray quadrupole time-of-flight mass spectrometry. Rapid Commun Mass Spectrom 2004;17:149-154.

54. Lopes NP, Almeida-Paz FA, Gates PJ. Influence of the alkal metal cation on the fragmentation of monensin in ESI-MS/MS. Braz J Pharm Sci 2006;42:363-367.

55. Degani H, Friedman HL. Ion binding by X-537A. Formulas, formation constants, and spectra of complexes. Biochemistry 1974; $13: 5022-5032$.
56. Painter G, Pressman BC. Induced fit as a determinative of ionophore selectivity. Biochem Biophys Res Comm 1979;91:1117-1122.

57. Painter G, Pressman BC. Circular dichroic discrimination of inclusion and peripheral complexes of the ionophore lasalocid $A$. Biochem Biophys Res Comm 1980;97:1268-1275.

58. Painter GR, Pollack R, Pressman BC. Conformational dynamics of the carboxylic ionophore lasalocid $A$ underlying cation complexation-decomplexation and membrane transport. Biochemistry 1982;21:5613-5620.

59. Shastri BP, Easwaran KRK. Conformations of lasalocid Alithium complexes in acetonitrile. Inter J Biol Macromol

1984;6:219-223.

60. Miles AJ, Hoffmann SV, Tao Y, Janes RW, Wallace BA. Synchrotron radiation circular dichroism (SRCD) spectroscopy: new beamlines and new applications in biology. Spectroscopy 2007;21:245-255.

61. Miles AJ, Janes RW, Brown A, Clarke DT, Sutherland JC, Tao Y, Wallace BA, Hoffmann SV. Light flux density threshold at which protein denaturation is induced by synchrotron radiation circular dichroism beamlines. J Synchrotron Radiat 2008;15:420422.

62. Frisch MJ, Trucks GW, Schlegel HB, Scuseria GE, Robb MA, Cheeseman JR, Scalmani G, Barone V, Mennucci B, Petersson GA, Nakatsuji H, Caricato M, Li X, Hratchian HP, Izmaylov AF, Bloino J, Zheng G, Sonnenberg JL, Hada M, Ehara M, Toyota K, Fukuda R, Hasegawa J, Ishida M, Nakajima T, Honda Y, Kitao O, Nakai H, Vreven T, Montgomery Jr JA, Peralta JE, Ogliaro F, Bearpark M, Heyd JJ, Brothers E, Kudin KN, Staroverov VN, Kobayashi R, Normand J, Raghavachari K, Rendell A, Burant JC, lyengar SS, Tomasi J, Cossi M, Rega N, Millam JM, Klene M, Knox JE, Cross JB, Bakken V, Adamo C, Jaramillo J, Gomperts R, Stratmann RE, Yazyev O, Austin AJ, Cammi R, Pomelli C, Ochterski JW, Martin RL, Morokuma K, Zakrzewski VG, Voth GA, Salvador P, Dannenberg JJ, Dapprich S, Daniels AD, Farkas O, Foresman JB, Ortiz JV, Cioslowski J, Fox DJ. Gaussian 09, Revision D01. Wallingford CT: Gaussian, Inc.; 2009. 63. Becke AD, Density-functional thermochemistry. III. The role of exact exchange. J Chem Phys 1993;98:5648-5652.

64. Klamt A. COSMO and COSMO-RS. In: Schleyer PR, Allinger NL, Clark T, Gasteiger J, Kollman PA, Schaefer III HF, Schreiner PR, editors. Encyclopedia of Computational Chemistry. Chichester: John Wiley \& Sons;1998. p 604-615.

65 . Bouř $P$, Keiderling TAJ, Partial optimization of molecular geometry in normal coordinates and use as a tool for simulation of vibrational spectra. Chem Phys 2002;117:4126-4132.

66. Dolg M. Relativistic effective core potentials. In:

Schwerdtfeger P., editor. Relativistic Electronic Structure Theory. Part I: Fundamentals. Amsterdam: Elsevier;2002. p 793-862.

67. Furche F, Ahlrichs R, Wachsmann C, Weber E, Sobanski A, Vögtle F, Grimme S. Circular dichroism of helicenes investigated by time-dependent density functional theory. J Am Chem Soc 2000;122:1717-1724.

68. Malfreyt P, Juillard J, Pascal Y. Structure of the ionophore monensin and of its tetramethylammonium salt - molecular modeling using various computational methods. New $\mathrm{J}$ Chem 1997;21:317-328

69. Heifets A, Lilien R. LigAlign: flexible ligand-based active site alignment and analysis. J Mol Graph Modell 2010;29:93-101. 70. Bruhn T, Schaumlöffel A, Hemberger Y, Bringmann G. SpecDis: Quantifying the comparison of calculated and experimental electronic circular dichroism spectra. Chirality 2013:25:243-249. 